doc. dr. sc. Ivana Načinović Braje

Ekonomski fakultet, Sveučilište u Zagrebu, Zagreb, Republika Hrvatska ivana.nacinovic@efzg.hr

Luka Bosnić, mag. oec.

Corrado d.o.o. Mostar

info@corrado.ba

\title{
NAGRAĐIVANJE ZAPOSLENIKA U MALIM PODUZEĆIMA: STANJE I ULOGA IZ PERSPEKTIVE MENADŽERA
}

Pregledni rad

\section{Sažetak}

Upravljanje nagrađivanjem važna je funkcija upravljanja ljudskim potencijalima. U cilju jačanja tržišne konkurentnosti, privlačenja i zadržavanja ključnih zaposlenika i mala poduzeća moraju posvetiti odgovarajuću pozornost kompenzacijama zaposlenih. U malim je poduzećima upravljanje ljudskim potencijalima, pa time i nagrađivanje, manje formalizirano te se dostupne teorijske spoznaje o upravljanju nagrađivanjem koje vrijede za velika poduzeća ne mogu bezuvjetno primijeniti i na mala poduzeća. U malim poduzećima menadžeri/vlasnici samostalno formuliraju odgovarajuće pakete kompenzacija koji bi trebali imati učinak na privlačenje, motiviranje i zadržavanje zaposlenika.

U cilju utvrđivanja stanja i uloge nagrađivanja u malim poduzećima provedeno je istraživanje među menadžerima malih poduzeća u Bosni i Hercegovini. Opće je mišljenje ispitanika da kompenzacije uglavnom nisu ključan element u privlačenju i zadržavanju zaposlenika u malim poduzećima. Ipak, postoje razlike s obzirom na poziciju ispitanika. Naime, svijest o važnosti kompenzacija veća je kod direktora malih poduzeća koji nisu ujedno i vlasnici poduzeća. Dodatna analiza različitih kategorija materijalnog i nematerijalnog nagrađivanja u poticanju motivacije i zadovoljstva zaposlenika u malom poduzeću pokazala je da je prema mišljenju ispitanika visina osnovne plaće ključan faktor u poticanju motivacije $i$ zadovoljstva zaposlenika. Pored materijalnog nagradivanja u vidu osnovne plaće odgovarajuće visine, ispitanici pridaju tek neznatno manju važnost kvaliteti radnog života i delegiranju odgovornosti, odnosno kategorijama nematerijalnog nagrađivanja. Iako menadžeri malih poduzeća ne smatraju da su kompenzacije presudne za motivaciju zaposlenika, svjesni su važnosti pojedinačnih kompenzacija, kako materijalnih, tako i onih nematerijalnih. 
Ključne riječi: nagrađivanje zaposlenika, materijalne kompenzacije, nematerijalne kompenzacije, mala poduzeća

JEL: M52

\section{UVOD}

Snažniji interes javnosti za mala poduzeća započeo je još osamdesetih godina prošlog stoljeća te traje i danas budući da brojni istraživači, teoretičari, ali i mnogi drugi, ukazuju da mala poduzeća u velikoj mjeri potiču i doprinose razvoju gospodarstva, konkurentnosti i zapošljavanju (Buble i Klepić, 2007.:9.). Teorija i praksa razlikuju mala i srednja poduzeća od velikih poduzeća te mala i srednja poduzeća (MSP) često svrstavaju u istu skupinu i analiziraju zajedno. MSP smatraju se okosnicom, kako razvijenih ekonomija, tako i ekonomija u razvoju, te posjeduju veliki potencijal za stimuliranje gospodarskog rasta i inovativnosti, a u vremenu recesije djeluju kao stabilizatori (Varum i Rocha, 2013.).

Malo ili srednje poduzeće nije moguće jednoznačno odrediti s obzirom da praksa primjenjuje različite kriterije veličine na osnovu kojih se organizacije mogu kategorizirati kao male, srednje ili velike (Hernaus i Aleksić, 2016.:17.). Različite zemlje također različito definiraju mala i srednja poduzeća. Primjerice, u SAD-u je za klasifikaciju malih i srednjih poduzeća zadužen vladin odjel Small Business Administration (SBA). SBA za klasifikaciju koristi kriterije specifične za pojedine industrije (Robu, 2013.), a kao ključni kriteriji koriste se broj zaposlenih (većinom do 500 zaposlenika) i godišnji prihod (različit za pojedine sektore) (United States International Trade Commission, 2010.). U Japanu definicija MSP kombinira kriterije djelatnosti poduzeća, broja zaposlenih (50-100-300 zaposlenih, ovisno o djelatnosti) i kapitala. Posebnu kategoriju mikro poduzeća u Japanu čine proizvodna poduzeća s manje od 20 zaposlenika i poduzeća u uslužnim i komercijalnim djelatnostima s manje od 5 zaposlenih (Ministry of Economy, Trade and Industry, 1999.). Iako će se kriteriji razlikovati ovisno o specifičnosti gospodarske grane ili nacionalnom okruženju unutar kojeg se nalazi neka organizacija, moguće je prepoznati tri glavne kategorije kriterija: financijski (veličina prihoda, ukupna aktiva), tržišni (tržišni udio, broj kupaca, globalna pokrivenost) i fizički (broj zaposlenika, materijalni kapaciteti). Unatoč postojanju većeg broja mogućih kriterija, u praksi mnogih zemalja najčešći kriterij za definiranje veličine poduzeća je upravo broj zaposlenih (Hernaus i Aleksić, 2016.:17.).

Uslijed velikih razlika u definiranju malih i srednjih poduzeća među državama Europske unije (EU), Europska komisija preporučila je državama članicama 
upotrebu jedinstvenih kriterija za definiranje MSP. Kriteriji uključuju broj zaposlenih, godišnji opseg prodaje (prihod od prodaje), prosječni opseg aktive (kapitala) poduzeća te mjerila samostalnosti (udio vlasništva odnosno kontrole od strane drugih ili više poduzeća ne smije biti veći od 25\%) (Buble i Klepić, 2007.:25.). Prema preporuci, kategorija mikro, malog i srednjeg poduzetništva sastoji se od poduzeća koja zapošljavaju manje od 250 osoba i čiji godišnji promet ne prelazi 50.000.000 eura, i/ili čija ukupna godišnja bilanca ne prelazi 43.000 .000 eura. Pritom je malo poduzeće ono koje zapošljava manje od 50 osoba i čiji godišnji promet i/ili čija ukupna godišnja bilanca ne prelazi 10.000 .000 eura, dok je mikro poduzeće ono poduzeće koje zapošljava manje od 10 osoba i čiji godišnji promet i/ili čija ukupna godišnja bilanca ne prelazi 2.000.000 eura (Commission Recommendation 2003/361/EC, 2003.).

Mala i srednja poduzeća okosnica su svakog gospodarstva, a njihov značaj posebno se prepoznaje kroz udio u zaposlenosti, ukupno ostvarenom prihodu i izvozu. Mikro, mala i srednja poduzeća čine više od $95 \%$ svih poduzeća u zemljama OECD-a. Glavninu čine mikro poduzeća s udjelom od $83 \%$ u ukupnom broju poduzeća. Većina MSP-a ( $85 \%$ mikro poduzeća i $72 \%$ malih i srednjih poduzeća) djeluje u uslužnom sektoru, pogotovo u trgovini na veliko i maloprodaji. MSP zapošljavaju dvije trećine ukupno zaposlenih u razvijenim zemljama i zemljama u razvoju. Njihov doprinos BDP-u je oko 35\% u zemljama u razvoju i oko $50 \%$ u razvijenim zemljama (World Trade Organization, 2016.). U EU u 2015. godini nešto manje od 23 milijuna malih i srednjih poduzeća ostvarilo je 3,9 milijardi eura dodane vrijednosti i zapošljavalo 90 milijuna ljudi. MSP su zapošljavala dvije trećine ukupno zaposlenih osoba u EU i kreirala nešto manje od tri petine ukupno kreirane dodane vrijednosti u nefinancijskom poslovnom sektoru (Europska komisija, 2016.).

Veliki doprinos malih i srednjih poduzeća ogleda se i u segmentu zapošljavanja. U kategoriji MSP-a u 2014. godini građevinski i proizvodni sektor, te sektori trgovine i distribucije, zajedno su zapošljavali 58,4\% ukupne radne snage u MSP. Čak $93 \%$ svih poduzeća u EU su mikro poduzeća koja imaju udio od $20 \%$ u stvaranju nove vrijednosti. Mikro poduzeća u uslužnim djelatnostima zapošljavaju više nego bilo koja druga kategorija poduzeća, osim u sektorima transporta, skladištenja i administracije. Doprinos malih i srednjih poduzeća stvaranju nove vrijednosti je manji nego njihov doprinos ukupnoj zaposlenosti, što rezultira nižom razinom produktivnosti rada u MSP (Eurostat, 2017.). Rast broja malih i srednjih poduzeća u eurozoni bio je veći nego u SAD-u u svim sektorima, posebice u proizvodnji gdje je broj MSP-a u SAD-u bio manji 2013. nego 2008. godine (OECD, 2016.) 
S obzirom na važnost za europsko gospodarstvo, MSP su u žarištu gospodarske politike EU-a. Cilj je Europske komisije poticati poduzetništvo i poboljšati poduzetničku klimu za MSP omogućujući im tako da ostvare svoj puni potencijal u današnjem globalnom gospodarstvu (Europska komisija, 2015.). Bez adekvatne ekonomske politike MSP suočavaju se s brojnim preprekama za rast i razvoj, posebice u kapitalno intenzivnim industrijama gdje su pristup financijama i integracija u globalne tokove ključne determinante uspjeha (OECD, 2016.). U zemljama u razvoju MSP primjenjujući radno intenzivne proizvodne metode doprinose efikasnijoj alokaciji resursa, čime osiguravaju uspostavljanje ravnoteže između veće raspoloživosti radne snage i nedostatka kapitala (Škrtić i Mikić, 2011.:13.). Osim toga, u usporedbi s velikim poduzećima, MSP su geografski ravnomjernije raspoređena, čime doprinose razvoju i difuziji poduzetničkih ideja i vještina i smanjenju ekonomskih razlika između urbanih i ruralnih područja (Škrtić i Mikić, 2011.:13.).

U Bosni i Hercegovini zbog nepostojanja jasne definicije i pristupa MSP na državnoj razini ne postoje dosljedni izvori podataka o tom sektoru na razini države. Zbog izostanka koordinacije i zajedničkih statističkih podataka o MSP nužno je kombinirati različite izvore podataka kako bi dobili broj MSP-a u Bosni i Hercegovini. Kombiniranjem i analizom podataka iz različitih izvora Džafić i Bejić (2012.) su prikazali strukturu MSP-a u BiH koja ukazuje da najveći broj poduzeća pripada kategoriji mikro poduzeća - 27.213 (do 10 zaposlenih) i njih je oko 65\% od svih MSP-a u Federaciji BiH, 84\% od svih MSP-a u Republici Srpskoj i 79\% od svih MSP-a u Distriktu Brčko. Malih poduzeća je 7.859 (do 50 zaposlenih) i njih je oko 27\% od svih MSP-a u Federaciji BiH, 12\% od svih MSP-a u Republici Srpskoj i 19\% od svih MSP-a u Distriktu Brčko. Srednjih poduzeća je ukupno 1.834, od toga 6,88\% od svih MSP-a u Federaciji BiH, 2,9\% od svih MSP-a u Republici Srpskoj i 0,58\% od svih MSP-a u Distriktu Brčko. U BiH je u MSP zaposleno 55\% od ukupnog broja zaposlenih osoba. Najveći broj MSP-a, $34,3 \%$ mikro poduzeća i 26,7\% malih poduzeća, posluje u djelatnosti trgovine na veliko i malo, dok 12,3\% mikro poduzeća i 19,8\% malih poduzeća pripada prerađivačkoj industriji (Ministarstvo privrede Kantona Sarajevo, 2016.).

Usporedbe radi, u Hrvatskoj je u 2015. godini bilo 106.221 mikro, malih i srednjih poduzeća (99,7\% ukupno registriranih poduzeća), koja su ostvarivala udio od 54\% u ukupnom prihodu, 69,2\% u zaposlenosti i 50,3 \% u izvozu Hrvatske i po sva ova tri kriterija u 2015. godini jačaju svoj udio i utjecaj na gospodarstvo Hrvatske u odnosu na prethodnu godinu (CEPOR, 2016.:7.).

Mala poduzeća imaju regionalnu ili lokalnu orijentaciju, organske i fleksibilne strukture koje su u pravilu vrlo jednostavne, a poduzetnici tj. najčešće i sami osnivači organizacije, imaju strogu kontrolu i drže ključne uloge unutar organizacije. 
Radna mjesta u malim poduzećima imaju široki djelokrug poslova i zadataka koje treba obaviti, dok u velikim poduzećima izvršioci trebaju obaviti najčešće jedan ili manji broj specijaliziranih zadataka (Hernaus i Aleksić, 2016.:19.). Globalizacijski procesi i konkurentski pritisci potiču organizacije svih veličina na optimizaciju poslovanja, a dinamičnim tržišnim uvjetima svojim poslovanjem moraju se prilagoditi i MSP, pri čemu pristup zaposlenicima može imati važnu ulogu. Naime, sve više raste svijest o utjecaju upravljanja ljudskim potencijalima na organizacijske rezultate i stvaranje održivih konkurentskih prednosti (Huselid, 1995., Cegarra-Leiva, Sánchez-Vidal, Cegarra-Navarro, 2012.).

Fokus ovog rada je otkrivanje karakteristika i specifičnosti nagrađivanja u malom poduzeću. Nagrađivanje zaposlenika privlači podjednaku pažnju zaposlenika i poslodavaca i osnova je po kojoj nastaju očekivanja s obje strane. Naime, kao posljedica zaposlenja u nekoj organizaciji javlja se implicitni psihološki ugovor, skup uvjerenja zaposlenika o tome što se od njih očekuje, te kakav odgovor mogu očekivati od poslodavca za poduzete akcije (Armstrong, 2005.). Među recipročnim očekivanjima između zaposlenika i poslodavaca, jedno je od ključnih očekivanja zaposlenika da budu kompenzirani u skladu s doprinosom organizaciji. Iz perspektive zaposlenika, plaća utječe na životni standard, status i sigurnost. S druge strane, iz perspektive poslodavca, kompenzacije predstavljaju trošak koji se mora kontrolirati, odnosno, investiciju koja mora ostvariti povrat u smislu stavova, znanja i vještina zaposlenika i učinkovitosti cijele organizacije (Gerhart, Milkovich i Murray, 1992.).

Upravljanje nagrađivanjem u malom poduzeću, kao nezaobilaznom funkcijom upravljanja ljudskim potencijalima, podrazumijeva uvažavanje specifičnosti vezanih za uvjete u kojima posluju mala poduzeća. Iako se mala i srednja poduzeća često svrstavaju u istu skupinu i analiziraju zajedno, te se samim time izjednačuju teorijske spoznaje o primijenjenih praksama u malim i srednjim poduzećima, u istraživanju provedenom u ovom radu uključena su uglavnom mala poduzeća. Kreiranje adekvatnih sustava nagrađivanja i atraktivnih kompenzacijskih paketa predstavlja veliki izazov za menadžere i vlasnike malih poduzeća, prvenstveno zbog pomanjkanja financijskih resursa, kao i zbog velikog utjecaja nagrađivanja na uspješnost poslovanja. Način na koji će biti oblikovan sustav nagrađivanja uvelike ovisi o tome kako menadžeri doživljavaju ulogu kompenzacija. Upravo stoga se u radu, pored iznošenja teorijskih spoznaja o nagrađivanju u malim poduzećima, analiziraju percepcije menadžera malih poduzeća o ulozi nagrađivanja u malom poduzeću. Poseban predmet interesa je analiza i utvrđivanje varijacija u ovisnosti na koji se način donose odluke o nagrađivanju, odnosno donosi li ih vlasnik ili direktor poduzeća. Ipak, s obzirom da se dostupni teorijski izvori referiraju na mala i srednja poduzeća, teorijske spoznaje prikazane u radu osim za mala poduzeća, često vrijede i za srednja poduzeća. 


\section{SPECIFIČNOSTI MLJP-A I NAGRAĐIVANJA U MALOM PODUZEĆU}

\subsection{MLJP u malim poduzećima}

U okviru menadžmenta ljudskih potencijala (MLJP) relativno rijetko se ispituje problematika i specifičnosti MLJP-a malih ili srednjih poduzeća. Štoviše, akademski interes za MLJP-a u malim i srednjim poduzećima uvelike je zapostavljen pred velikim poduzećima (Tansky i Heneman, 2003.), a dostupno znanje o upravljanju ljudskim potencijalima u malim poduzećima previše deskriptivno i fragmentirano (Brand i Bax, 2002.). Uslijed razlika između velikih te malih i srednjih poduzeća te dodatnih specifičnih obilježja malih poduzeća potrebno je provesti posebna istraživanja na malim i srednjim poduzećima, jer zaključci iz istraživanja velikih poduzeća ne mogu biti izravno primijenjeni na mala i srednja poduzeća (Tansky i Heneman, 2003., Carlson i sur., 2006.). Dodatno, postoji sumnja da li se ionako malobrojna istraživanja provedena u okruženju razvijenih zapadnih zemalja mogu primijeniti na MLJP u zemljama istočne ili Jugoistočne Europe (Carraher i Carraher, 2006., Psychogios i sur., 2016.).

Između veličine poduzeća i upravljanja ljudskim potencijalima postoji snažna veza (Brewster i sur., 2006.). U usporedbi s velikim poduzećima, upravljanje ljudskim potencijalima u malim poduzećima je manje profesionalizirano i s manje pisanih politika (De Kok i sur., 2006. prema Cegarra-Leiva, Sánchez-Vidal i Cegarra-Navarro, 2012.), odnosno nije nužno formalizirano (Psychogios i sur., 2016.). U širem smislu formalna politika MLJP-a podrazumijeva da je praksa ili politika opisana u pisanom obliku ili se redovito primjenjuje u organizaciji (Psychogios i sur., 2016., Barrett i Mayson, 2007.). Mala i srednja poduzeća primjenjuju neformalni pristup upravljanju ljudskim potencijalima te intuitivni i ad hoc pristup funkcijama MLJP-a jer formalizacija zahtijeva troškove i kreiranje posebnog odijela (Cunningham i Rowley, 2007. prema Prouska, Psychogios i Rexhepi, 2016.). Vlasnici/menadžeri malih poduzeća često formalne prakse MLJP-a doživljavaju kao dodatni zamah birokratiziranosti (Singh i Vohra, 2009.). Uslijed tih razloga mala poduzeća nemaju odjele za ljudske potencijale, a većinu odluka vezanih uz problematiku upravljanja ljudskim potencijalima donosi samostalno vlasnik ili direktor poduzeća (Psychogios i sur., 2016.). Kako poduzeća rastu, formalizacija MLJP-a postaje poželjna, međutim, mogućnost da se to uistinu i dogodi ovisi o tome da vlasnik/direktor uvidi potrebu za delegiranjem te funkcije, kao i mogućnostima da se funkcija MLJP-a uistinu delegira (Barrett i Mayson, 2007.).

Prema rezultatima istraživanja MLJP-a u MSP u Jugoistočnoj Europi (Psychogios i sur., 2016.) stupanj formalizacije MLJP-a uvjetovan je s tri ključna faktora: 
geografskom opsegu poslovanja (međunarodno ili lokalno), pripadajućem sektoru (proizvodnja ili maloprodaja i usluge) i veličini organizacije (mala ili velika). Na formalizaciju funkcije ljudskih potencijala u MSP Jugoistočne Europe značajno utječe internacionalizacija. Poduzeća koja su više internacionalizirana i uključena u međunarodnu razmjenu češće imaju formalno uspostavljen odjel upravljanja ljudskim potencijalima. Osim toga, multinacionalna poduzeća češće uvode programe obuke i formaliziraju komunikaciju i kompenzacijske sustave (Newman i Sheikh, 2014., Psychogios i sur., 2016.).

Među brojne funkcije, odnosno aktivnosti, MLJP-a (Bahtijarević-Šiber, 1999.) spada i nagrađivanje zaposlenika. Upravljanje nagrađivanjem, odnosno kompenzacijski menadžment, obuhvaća oblikovanje, provođenje i održavanje sustava nagrađivanja koji pomaže poduzeću da ostvari strateške ciljeve (Galetić, 2015.:50.). Sustavi nagrađivanja imaju ključnu ulogu u privlačenju novih zaposlenika, motiviranju i zadržavanju zaposlenika, poboljšavanju performansi organizacije i održavanju radnog angažmana i posvećenosti zaposlenika organizaciji (Galetić, 2015., Kerrin i Oliver, 2002., Day i sur., 2014., Tomaževič i sur., 2014, prema Prouska, Psychogios i Rexhepi, 2016.). Prepoznato je da je nagrađivanje jedna od funkcija MLJP-a kritična za opću uspješnost čitave organizacije (Gerhart i Milkovich, 1992., Carlson, Upton i Seaman, 2006.).

U početnim fazama razvoja malih poduzeća, u uvjetima malog broja zaposlenika i olakšane komunikacije, zaposlenici će blisko surađivati s vlasnikom koji će ih poticati na izvršavanje poslovnih ciljeva. Sustavi nagrađivanja bit će kaotični i personalizirani, a rijetko rezultat sustavnog pristupa problematici nagrađivanja zaposlenika (Armstrong i Murlis, 2004.). Ipak, upravo s rastom poduzeća gubit će se veza zaposlenika s vlasnikom/menadžerom te će rasti uloga poticaja i sustava nagrađivanja u postizanju količine i kvalitete učinka (Richbell, Szerb i Vitai, 2010.).

\subsection{Nagrađivanje u malim poduzećima}

Generalno gledajući, uloga nagrađivanja je jednaka u svim poduzećima bez obzira na veličinu. Temeljni ciljevi kompenzacijskog menadžmenta kao što su pridobivanje, zadržavanje i motiviranje kvalitetnih ljudskih resursa koji će osigurati ostvarenje ciljeva poduzeća (Buble i Bakotić, 2013.:42.) vrijede i za mala poduzeća, pri čemu nagrađivanje zaposlenika, sustavno ili ne, u pravilu nije previše opseženo i kontrolirano je najčešće samo od vlasnika ili menadžera malog poduzeća.

Krajnji kompenzacijski paket predstavlja sve kompenzacije koje zaposlenici primaju od poslodavca za obavljeni rad u poduzeću. Sustav nagrađivanja uključuje 
dvije skupine nagrada: transakcijske nagrade, temeljene na materijalnim nagradama, te transformacijske nagrade intrinzičnog karaktera (Martocchio, 2015.). Materijalne nagrade su pritom prepoznate kao ključni faktor koji se daje zaposlenicima u zamjenu za ostvareni doprinos (Milkovich i Newman, 2005., Heneman i Judge 2000.).

Na tržištu rada mala poduzeća natječu se za radnu snagu sa svim ostalim organizacijama, ali su njihove financijske mogućnosti često ograničene te su plaće $u$ malim poduzećima u pravilu manje negoli plaće u velikim poduzećima (Galetić, 2015). Ipak, usprkos ograničenim resursima, privlačenje i zadržavanje talenata je posebno kritično za mala poduzeća koja obilježavaju poduzetničke pothvate (Brush i sur., 2001.) te u cilju pribavljanja, motiviranja i zadržavanja kvalitetnih zaposlenika u konkurenciji s velikim poduzećima i MSP trebaju osigurati atraktivne kompenzacijske pakete (Mayson i Barrett, 2006.). Upravo uslijed ograničenih resursa mala poduzeća ponekad imaju tendenciju izbjeći primjenu najboljih praksi upravljanja ljudskim potencijalima zbog visokih troškova usvajanja takvih praksi (Newman i Sheikh, 2014.). Aktivnosti privlačenja kvalitetnih zaposlenika mogu biti posebno zahtjevne zbog činjenice da se u tranzicijskim društvima mala poduzeća ne percipiraju kao najpoželjniji poslodavci. Naime, u tranzicijskim ekonomijama sigurnost posla i veće plaće čine velika državna poduzeća još uvijek privlačnijim poslodavcima u odnosu na mala poduzeća koja su većinom u privatnom vlasništvu.

Prakse nagrađivanja u malim i srednjim poduzećima su neformalne i bazirane na ad hoc pristupu (Wilkinson, 1999. prema Prouska, Psychogios i Rexhepi, 2016.). U nekim slučajevima postoji privid sustavnog pristupa nagrađivanju, međutim u stvarnosti je nagrađivanje često pod velikim utjecajem prethodnih iskustava i predrasuda menadžera/vlasnika (Armstrong i Murlis, 2004.). Zanimljivo, De Kok, Uhlander i Thurik (2002.) istraživanjem nisu potvrdili povezanost veličine poduzeća i formalizacije nagrađivanja i ocjene radne uspješnosti. Ipak, upravo neformalnost može biti prednost za MSP u kojima informacije koje se dijele između vlasnika/menadžera i zaposlenika rezultiraju u visokom stupnju zaposleničke participacije u odlučivanju (Richbell i sur., 2010. prema Prouska, Psychogios i Rexhepi, 2016.).

Za razliku od velikih poduzeća, mala si poduzeća mogu dopustiti fleksibilnost te u nagrađivanju zaposlenika često izostaju klasične procjene poslova i formalne platne strukture (Gilman i sur., 2002.). Važna determinanta koja pridonosi neformalnosti utvrđivanja osnovne plaće za pojedini posao/osobu je i sindikaliziranost (Deshpande i Flanagan, 1995.), odnosno činjenica da u malim poduzećima u pravilu nema sindikata koji bi utjecali na oblikovanje sustava nagrađivanja. Curran i sur. (1993,.: 147.) ukazuju da se u malim poduzećima u uslužnom sektoru, plaća 
tipično utvrđuje pregovaranjem između zaposlenika i poslodavca ili jednostrano od strane poslodavca (Curran i sur., 1993.). Poznato je također da snažan utjecaj na plaće i sustave nagrađivanja u malim i srednjim poduzećima ima konkurencija (Rainnie, 1989. prema Gilman i sur., 2002.) i tržište (Gilman i sur., 2002.).

Razina formalizacije ostalih aspekata nagrađivanja može se razlikovati (Psychogios i sur., 2016.). Osim vrlo niske formalizacije u pogledu formalnih procjena poslova, u MSP jugoistočne Europe primijećena je osrednja formalizacija općenitog sustava nagrađivanja ili sustava beneficija, te nešto niža formalizacija varijabilnog nagrađivanja (Gilman i sur., 2002.). Formalizacija praksi nagrađivanja ovisi i o načinu upravljanja, u MSP u obiteljskom vlasništvu u kojima je direktor ujedno vlasnik poduzeća formalizacija je manja nego u poduzećima u kojima direktor nije član obitelji vlasnika (Michiels, 2017.).

U kategoriji materijalnih nagrada, mala i srednja poduzeća uz osnovnu plaću koriste i plaćanje prema učinku (Zhend i sur., 2007.). Gilman i sur. (2002.) ukazuju da manje od polovice MSP primjenjuje neki od oblika varijabilnog nagrađivanje, a tek trećina primjenjuje sustave plaćanja po učinku. Ipak, recentnija istraživanja ukazuju na rastuću primjenu sustava nagrađivanja prema učinku u MSP-a (Newman i Sheikh, 2014.). Poznato je također da u MSP u obiteljskom vlasništvu, u kojima vlasnici upravljaju poduzećem ili je namjeravana transgeneracijska sukcesija, postoji manja sklonost korištenju poticajnog nagrađivanja za menadžere i zaposlenike (Memili i sur., 2013.).

Iako je plaćanje vezano uz učinak i ocjenjivanje radne uspješnosti kod MSP vrlo malo korišteno, upravo se korištenje ocjenjivanja radne uspješnosti pokazalo važnom razlikom između brzo rastućih malih i srednjih poduzeća u usporedbi sa sporo rastućim MSP (Carlson, Upton i Seaman, 2006.). Na usvajanje sustavnog ocjenjivanja učinka i primjenu nagrađivanja prema učinku značajno utječe razina obrazovanja izvršnih direktora MSP-a (Newman i Sheikh, 2014.).

Pozitivan učinak primjene ocjenjivanja zaposlenika i varijabilnog nagrađivanja na učinkovitost malih i srednjih poduzeća potvrdili su King-Kauanui, Ngoc i Ashley-Cotleur, (2006.). Ipak, iako je često isticana važnost poticajnog nagrađivanja u upravljanju ljudskim potencijalima (Huselid, 1995), određena istraživanja ukazuju da na rast malih poduzeća još snažniji pozitivni učinak može imati primjena kompenzacija u obliku sudjelovanja u kapitalu (Brush i sur., 2001., Arbaugh, Cox i Camp, 2004.). Slično, i profit sharing ima snažniji poticajni efekt kod malih poduzeća od većih poduzeća jer se na taj se način diverzificira rizik povezan s potrebnom ostvarivanja prihoda, ali i reducira rizik otkaza ili propasti poduzeća (Mukhopadhyay i Pendse, 1983.) 
Umjesto financijski zahtjevnijih materijalnih nagrada, u sustav nagrađivanja moguće je implementirati i nematerijalne nagrade i poticaje. Iako MSP stoje na raspolaganju brojne opcije za oblikovanje i razvoj politika i praksa za unaprjeđenje kvalitete radnog života, menadžeri MSP se rijetko odlučuju na usvajanje tih praksi. Kao glavni razlozi navode se nedostatak resursa, nedostatak kvalificirane radne snage i nedostatak jednostavnih i pristupačnih rješenja za unaprjeđenje kvalitete radnog života koja su prilagođena primjeni u MSP (Cegarra-Leiva, Sánchez-Vidal i Cegarra-Navarro, 2012.). U velikim poduzećima prakse unaprjeđenja kvalitete radnog života su formalizirane, dok u malim poduzećima menadžeri pojedinačno pristupaju pregovaranju o uvjetima rada sa zaposlenicima. Menadžeri malih i srednjih poduzeća uglavnom uvode prakse za unaprjeđenje kvalitete radnog života na temelju zahtjeva zaposlenika i odlučuju se na implementaciju istih očekujući reciprocitet (Cegarra-Leiva, Sánchez-Vidal i Cegarra-Navarro, 2012.). Primjerice, zaposlenici cijene mogućnost da radno vrijeme prilagođavaju svojim potrebama ili da zadatke izvršavaju od kuće ako priroda posla to dozvoljava. Mnoge velike tvrtke nisu u mogućnosti zaposlenicima pružiti tu vrstu slobode jer menadžeri strahuju od gubitka kontrole (StinesBrian i Kleiner, 2003.).

Bolje radno okruženje pozitivno utječe na poboljšanje performansi organizacije. Dokazana je pozitivna veza između organizacijskih performansi i kvalitete radnog života, zaposleničke participacije i organizacijske kulture koja podržava osobni i profesionalni razvoj (Cegarra-Leiva, Sánchez-Vidal i Cegarra-Navarro, 2012.). Ove prakse mogu biti održivo rješenje za male organizacije koje posluju u lošim ekonomskim uvjetima (Prouska, Psychogios i Rexhepi, 2016.).

MSP će vjerojatnije kombinirati materijalne i nematerijalne nagrade, odnosno usvojiti model ukupne nagrade, ako prate strategiju promicanja bliskih i skladnih odnosa među zaposlenicima, osiguravaju bolje radno okruženje koje karakterizira kvalitetan menadžment, neformalna komunikacija, fleksibilnost, participacija zaposlenika, posvećenost i povjerenje (Wilkinson, 1999. prema Prouska, Psychogios i Rexhepi, 2016.) U protivnom, mala poduzeća koja ne promiču samostalnost i participaciju zaposlenika, koja imaju loše uvjete rada, loše zdravstvene i sigurnosne uvjete, male materijalne nagrade, nisku razinu zadovoljstva zaposlenih i njihovog zadržavanja u poduzeću, veliku ukupnu stopu izostanka i fluktuacije zaposlenih vjerojatno nemaju ili koriste samo mali broj komponenata ukupne nagrade (Cunningham i Rowley, 2010. prema Prouska, Psychogios i Rexhepi, 2016.). Barrett i Mayson (2007.) ukazuju da rastuća MSP češće od ostalih organizacija primjenjuju kombiniranje materijalnih i nematerijalnih nagrada u cilju poticanja predanosti zaposlenika.

Oblikovanje sustava nagrađivanja uključuje izbor između niza materijalnih i nematerijalnih nagrada, pri čemu menadžeri moraju izvršiti selekciju te odabrati i primijeniti one elemente koji najbolje odgovaraju specifičnostima organizacije 
(Thorpe i Homan, 2000.). Ipak, pozicija menadžera bez vlasničkog udjela i menadžera-vlasnika se pri tome može razlikovati. Naime, menadžeri-vlasnici mogu imati dugoročniju perspektivu u odlučivanju i pažljivije koristiti resurse kojima organizacija raspolaže, uključujući i izdatke za plaće zaposlenika. U svakom slučaju, konačni učinak nagrada ovisiti će o tome kako će pojedinci doživljavati nagrade (Miceli i Lane, 1991.)., odnosno o njihovom zadovoljstvu plaćom.

\section{EMPIRIJSKO ISTRAŽIVANJE}

Za potrebe provođenja istraživanja percepcija menadžera malih poduzeća o ulozi i važnosti nagrađivanja korišteni su primarno prikupljeni podaci. Istraživanje je provedeno metodom on - line ankete, na prigodnom uzorku $(n=59$ ispitanika) menadžera malih poduzeća u Bosni i Hercegovini. Na temelju dostupne teorije o kompenzacijama, kao i ranije provedenih istraživanja, ispitane su percepcije menadžera malih poduzeća o faktorima koji utječu na visinu plaće, te percepcije o motivacijskom potencijalu materijalnog i nematerijalnog nagrađivanja. U sljedećoj tablici može se vidjeti profil poduzeća obuhvaćenih istraživanjem.

Tablica 1: Profil analiziranih poduzeća

\begin{tabular}{|l|l|}
\hline \multicolumn{1}{|c|}{ Obilježje } & \multicolumn{1}{|c|}{ Udio u uzorku } \\
\hline Broj zaposlenika & $\begin{array}{l}\text { 1-19 zaposlenika 70,4\%; 20-49 zaposlenika 22,2\%; više od 50 za- } \\
\text { poslenika 7,4\% }\end{array}$ \\
\hline Djelatnost & $\begin{array}{l}\text { Proizvodnja 24,1\%; Uslužne djelatnosti 44,4\%; Trgovačka djelatno- } \\
\text { sti 18,5\%; Kombinacija više djelatnosti 13\% }\end{array}$ \\
\hline Godišnji prihod & $\begin{array}{l}0-400.000 \mathrm{KM} \text { (oko 200.000 EUR) 44,4\%, 400.000 KM (oko } \\
200.000 \text { EUR) - 4.000.000 KM (oko 2.000.000 EUR 40,7\%, Više } \\
\text { od 4.000.000 KM (oko 2.000.000 EUR) } 13 \%\end{array}$ \\
\hline
\end{tabular}

Kao što je vidljivo iz tablice 1, u uzorku su najviše zastupljeni ispitanici iz poduzeća s manje od 19 zaposlenih, koja posluju u uslužnim djelatnostima, čiji je ukupni godišnji prihod manji od 400.000 KM (oko 200.000 EUR). Očekivano najveći broj poduzeća u uzorku, njih $52,80 \%$, pripada mikro poduzećima $(0-9$ zaposlenih), koji ujedno imaju najveći udio u ukupnom broju malih i srednjih poduzeća u BiH (oko 65\% svih MSP u Federaciji BiH i 84\% svih MSP u Republici Srpskoj). Ukupno 7,4\% analiziranih poduzeća zapošljava više od 50 zaposlenika te time zadovoljavaju jedan od kriterija za klasifikaciju u skupinu srednjih poduzeća, međutim u uzorak su uključena isključivo poduzeća iz populacije malih poduzeća te se vjerojatno radi o poduzećima čiji broj zaposlenika tek neznatno prelazi 50 te su stoga uključena u daljnju analizu i klasificirana kao mala poduzeća. U uzorku $28,30 \%$ ispitanih menadžera malih poduzeća čine žene, dominiraju menadžeri sa završenom visokom školom $(48,15 \%)$ i većinom iz dobne skupine 30-40 godina (35,85\% ispitanih menadžera). 
S obzirom na specifičnosti organizacije i upravljanja malih poduzeća, te često spojenu funkciju vlasništva i upravljanja, u prvom je koraku utvrđena odgovornost za problematiku nagrađivanja. Niti u jednom od poduzeća iz uzorka ne postoji zasebna pozicija odnosno zaposlenik koji bi bio zadužen samo za plaće zaposlenika. Ovi rezultati govore da su u malim poduzećima odluke o plaćama i ključnim područjima politike nagrađivanja očekivano centralizirane i donose ih menadžeri samostalno. Radi daljnje analize percepcija važnosti kompenzacija analiziran je položaj ispitanika, odnosno da li su ispitanici isključivo menadžeri bez većinskog vlasničkog udjela ili se radi o integriranoj ulozi vlasnika/menadžera te odluke o kompenzacijama donosi većinski vlasnik koji ujedno obnaša funkciju menadžera.

Slika 1: Profil menadžera malih poduzeća iz uzorka

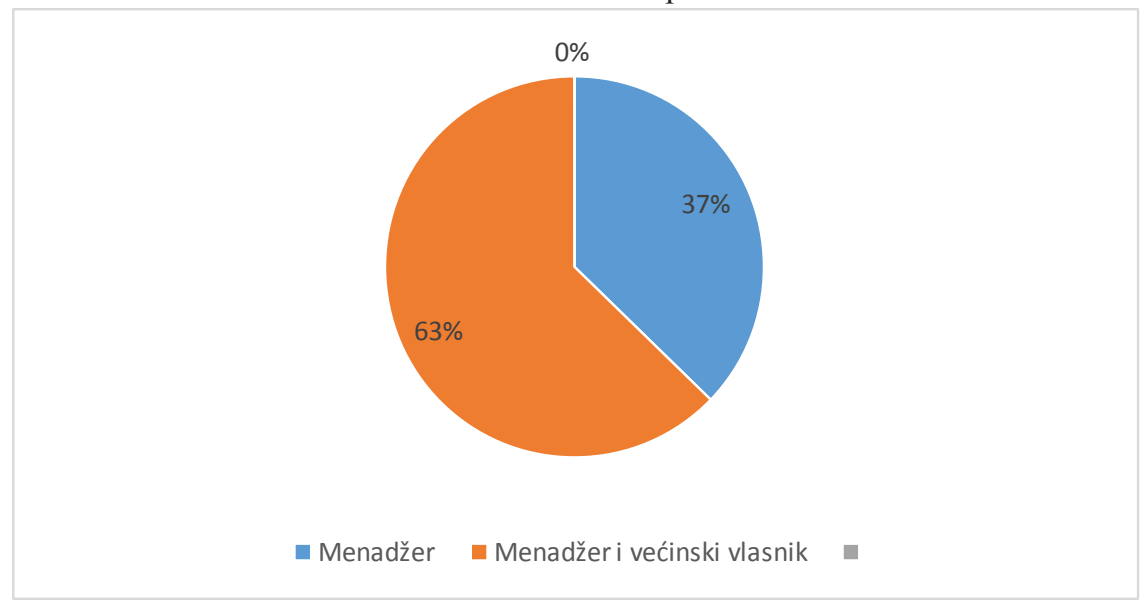

Izvor: obrada autora

Od 51 menadžera analiziranih poduzeća koji su definirali svoju poziciju u poduzeću, iz slike 1 je vidljivo da je u relativno najvećem dijelu poduzeća iz uzorka (63\%) ispitanik u poziciji većinskog vlasnika i menadžera. U relativno manjem dijelu uzorka (37\%) ispitanik je isključivo direktor poduzeća. U sljedećem je koraku ispitan opći stav ispitanika prema kompenzacijama kako bi se utvrdila važnosti kompenzacija u malim poduzećima, i iz perspektive donositelja odluka o kompenzacijama. 
Tablica 2: Percepcija važnosti kompenzacija u malim i srednjim poduzećima

\begin{tabular}{|c|c|c|c|c|c|c|}
\hline \multicolumn{6}{|c|}{ Kompenzacije imaju ključnu ulogu privlačenju i zadržavanju zaposlenika } \\
\hline Ispitanik & $\begin{array}{c}\text { Uopće se } \\
\text { ne slažem }\end{array}$ & $\begin{array}{c}\text { Ne slažem } \\
\text { se }\end{array}$ & $\begin{array}{c}\text { Ni slažem } \\
\text { ni ne sla- } \\
\text { žem se }\end{array}$ & $\begin{array}{c}\text { Slažem } \\
\text { se }\end{array}$ & $\begin{array}{c}\text { U pot- } \\
\text { punosti } \\
\text { se slažem }\end{array}$ & Ukupno \\
\hline Direktor & $5,26 \%$ & $5,26 \%$ & $36,84 \%$ & $26,32 \%$ & $26,32 \%$ & $100 \%$ \\
\hline $\begin{array}{c}\text { Većinski vla- } \\
\text { snik i direktor }\end{array}$ & $15,63 \%$ & $9,38 \%$ & $28,13 \%$ & $37,50 \%$ & $9,38 \%$ & $100 \%$ \\
\hline Ostalo & $33,33 \%$ & $66,67 \%$ & $0,00 \%$ & $0,00 \%$ & $0,00 \%$ & $100 \%$ \\
\hline Ukupno & $12,96 \%$ & $11,11 \%$ & $29,63 \%$ & $31,48 \%$ & $14,81 \%$ & $100 \%$ \\
\hline
\end{tabular}

Izvor: obrada autora

Rezultati prethodne analize pokazuju da se relativno najveći dio ispitanika iz uzorka $(31,48 \%)$ slaže s tvrdnjom da kompenzacije imaju ključnu ulogu u privlačenju i zadržavanju zaposlenika. S obzirom da se tvrdnja odnosi na ključne uloge kompenzacija iznenađuje značajan postotak ispitanika (ukupno 53,7\%) koji se ne bi složili da kompenzacije imaju važnu ulogu u privlačenju i zadržavanju zaposlenika (u rasponu od toga da se uopće ne slažu pa do toga da se ni slažu ni ne slažu). Ovakve je rezultate moguće tumačiti u kontekstu činjenice da mala poduzeća često imaju ograničene financijske resurse te ne mogu garantirati atraktivne kompenzacijske pakete. Ipak, s obzirom da je prethodno utvrđena pozicija ispitanika (direktor ili vlasnik i direktor) uočene su razlike u percepcijama s obzirom na ispitanike. Naime, svijest o važnosti kompenzacija puno je veća kod direktora malih poduzeća koji nisu ujedno i vlasnici poduzeća, $(52,64 \%$ uviđa važnost kompenzacija naspram 10,52\% ispitanika koji ne smatraju da kompenzacije imaju važnu ulogu u privlačenju i zadržavanju zaposlenika). Kod direktora koji su ujedno većinski vlasnici, njih $25 \%$ ne smatra da su kompenzacije ključne za privlačenje i zadržavanje zaposlenika.

Neformalan karakter upravljanja ljudskim potencijalima u malim poduzećima uvjetuje neformalan pristup kompenzacijama (Wilkinson, 1999.). Istraživanjem je ispitana važnost različitih elemenata za definiranje visine plaće zaposlenika malih poduzeća. 
Slika 2: Utjecaj različitih elemenata na utvrđivanje visine plaće

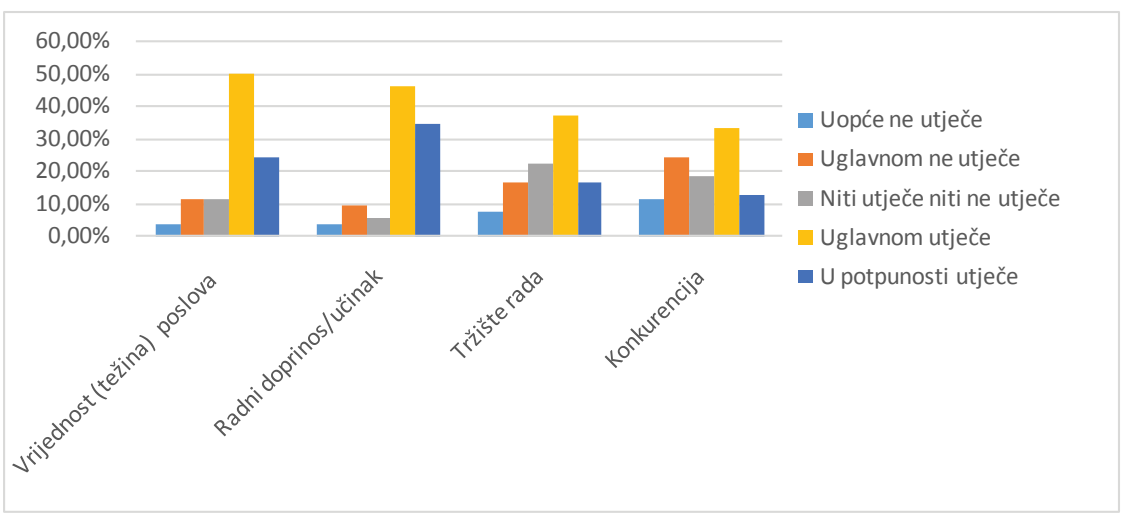

Izvor: obrada autora

Analizom je utvrđeno da prema percepciji ispitanika vrijednost (težina) posla i radni doprinos/učinak najviše utječu na utvrđivanje visine plaće, dok konkurentske prakse imaju najmanji utjecaj. Navedeno može upućivati da su mala poduzeća svjesna važnosti varijabilnog nagrađivanja te da ga primjenjuju u praksi. S druge strane, temeljem dobivenih rezultata može se zaključiti da mala poduzeća ne posvećuju veliku pažnju benchmarku, što se ponovno može pripisati ograničenim mogućnostima malih poduzeća u okviru kojih menadžeri moraju oblikovati kompenzacijske pakete svojih zaposlenika. Ipak, slika 2 pokazuje da svaki od elemenata, bez značajnih odstupanja, utječe na visinu plaće u malom poduzeću.

Tablica 3: Percepcije ispitanika o važnosti materijalnog nagrađivanja u poticanju motivacije i zadovoljstva zaposlenika u malom poduzeću

\begin{tabular}{|l|c|c|c|c|c|}
\hline & N & Min & Max & $\begin{array}{c}\text { Aritm. } \\
\text { sredina }\end{array}$ & SD \\
\hline Osnovna plaća & 54 & 1 & 5 & 4,28 &, 960 \\
\hline $\begin{array}{l}\text { Plaća vezana za učinak } \\
\text { kompetencije ili doprinos }\end{array}$ & 53 & 1 & 5 & 4,13 & 1,001 \\
\hline Novčani bonusi & 54 & 1 & 5 & 4,20 &, 959 \\
\hline Udio u vlasništvu & 54 & 1 & 5 & 2,93 & 1,503 \\
\hline Beneficije & 54 & 1 & 5 & 3,83 & 1,129 \\
\hline
\end{tabular}

Napomena: 1- Uopće se ne slažem; 5 - U potpunosti se slažem, $\mathrm{SD}=$ standardna devijacija Izvor: obrada autora

Prethodna tablica prikazuje percepcije ispitanika o ulozi različitih kategorija materijalnog nagrađivanja u poticanju motivacije i zadovoljstva zaposlenika u 
malom poduzeću. Osnovna plaća je ostvarila najveću prosječnu ocjenu od svih analiziranih kategorija materijalnog nagrađivanja ( $x=4,28, \mathrm{SD}=0,96)$. Visoko su ocijenjene i kategorije novčani bonusi, te plaća vezana za učinak, kompetencije ili doprinos. S druge strane, udio u vlasništvu je kategorija materijalnog nagrađivanja s najmanjom prosječnom ocjenom. Loša ocjena ove kategorije posljedica je vrlo rijetke primjene u malim poduzećima, te ispitanici u tom kontekstu očito ne percipiraju navedenu kategoriju kao relevantnu za veću motiviranost i zadovoljstvo zaposlenika. Osim toga, mala poduzeća su većinom u vlasništvu jedne ili dviju osoba, a u tim uvjetima vlasnička struktura se rijetko mijenja.

Ocjene ispitanika o ulozi različitih kategorija nematerijalnog nagrađivanja u poticanju motivacije i zadovoljstva zaposlenika u malom poduzeću prikazane su u tablici 4 .

Tablica 4: Percepcije ispitanika o ulozi nematerijalnog nagrađivanja u poticanju motivacije i zadovoljstva zaposlenika u malom poduzeću

\begin{tabular}{|l|c|c|c|c|c|}
\hline & N & Min & Max & $\begin{array}{c}\text { Aritm. } \\
\text { sredina }\end{array}$ & SD \\
\hline Priznanje za obavljen posao & 54 & 1 & 5 & 3,87 & 1,166 \\
\hline Dodjeljivanje odgovornosti & 53 & 1 & 5 & 4,21 &, 793 \\
\hline Značajan posao & 54 & 1 & 5 & 3,89 &, 984 \\
\hline Autonomija u radu & 54 & 1 & 5 & 3,76 & 1,045 \\
\hline $\begin{array}{l}\text { Mogućnost za uporabu i } \\
\text { razvoj vještina }\end{array}$ & 54 & 1 & 5 & 3,94 &, 979 \\
\hline Mogućnost za razvoj karijere & 53 & 1 & 5 & 4,06 & 1,064 \\
\hline Kvaliteta radnog života & 54 & 1 & 5 & 4,22 & 1,022 \\
\hline
\end{tabular}

Napomena: 1- Uopće se ne slažem; 5 - U potpunosti se slažem

Izvor: obrada autora

Analiza rezultata pokazuje da je većina ispitanika ponuđene kategorije nematerijalnog nagrađivanja ocijenila kao važne za zadovoljstvo i poticanje na veći angažman zaposlenika. Kategorije kvaliteta radnog života $(\bar{x}=4,22, \mathrm{SD}=1,02)$ i dodjeljivanje odgovornost $(x=4,21, \mathrm{SD}=0,78)$ imaju najveću prosječnu ocjenu, dok je kategorija autonomija u radu ostvarila najmanju prosječnu ocjenu $(x=3,76, \mathrm{SD}=1,05)$. Menadžeri malih poduzeća ne uviđaju važnost odavanja priznanja za dobro obavljen posao, a dio njih nije svjestan činjenice da mogućnosti za osobni razvoj zaposlenika (kroz razvoj vještina ili napredak u karijeri) također mogu imati veliki utjecaj na poticanje motivacije zaposlenika. Općenito, rezultati pokazuju da menadžeri malih poduzeća posvećuju određenu pozornost 
individualnim i kolektivnim relacijskim nagradama i svjesni su njihovih pozitivnih učinaka.

S obzirom da su neki ispitanici menadžeri i ujedno vlasnici poduzeća, dok drugi samo profesionalno obavljaju posao menadžera, analizom se pokušalo utvrditi postoje li razlike u percepcijama važnosti materijalnih i nematerijalnih kompenzacija između te dvije kategorije ispitanika. Deskriptivna analiza (Tablica 5) ukazuje da su menadžeri koji su ujedno i vlasnici svim analiziranim kategorijama nagrađivanja dali u prosjeku manju važnost za poticanje motivacije i zadovoljstva zaposlenika negoli menadžeri bez većinskog vlasničkog udjela u poduzeću.

Tablica 5: Analiza razlika u percepcijama važnosti materijalnog i nematerijalnog nagrađivanja menadžera i menadžera-vlasnika

\begin{tabular}{|l|c|c|}
\hline \multicolumn{1}{|c|}{ Element } & Vlasnik-menadžer & $\begin{array}{c}\text { Menadžer } \\
\text { (bez vlasništva) }\end{array}$ \\
\hline Osnovna plaća & 4,16 & 4,47 \\
\hline $\begin{array}{l}\text { Plaća vezana za učinak kompetencije ili do- } \\
\text { prinos }\end{array}$ & 4,03 & 4,42 \\
\hline Novčani bonusi & 4,09 & 4,37 \\
\hline Udio u vlasništvu & 2,84 & 3,16 \\
\hline Beneficije & 3,78 & 4,05 \\
\hline Priznanje za obavljen posao & 3,88 & 4,05 \\
\hline Dodjeljivanje odgovornosti & 4,16 & 4,26 \\
\hline Značajan posao & 3,8 & 3,89 \\
\hline Autonomija u radu & 3,66 & 4,05 \\
\hline Mogućnost za uporabu i razvoj vještina & 3,91 & 4,11 \\
\hline Mogućnost za razvoj karijere & 3,94 & 4,26 \\
\hline Kvaliteta radnog života & 4,09 & 4,47 \\
\hline
\end{tabular}

Izvor: obrada autora

U daljnjim je koracima proveden Mann-Whitney U test kako bi se statistički potvrdilo postojanje razlika u percepcijama važnosti nagrađivanja menadžera i vlasnika-menadžera. Međutim, analizom nisu utvrđene statistički značajne razlike u ispitivanim percepcijama, odnosno, nije moguće zaključiti da će menadžeri malih poduzeća koji nemaju vlasnički udio drugačije doživljavati važnost kompenzacija od menadžera koji ujedno posjeduju većinski vlasnički paket i takav zaključak generalizirati za cijelu populaciju malih poduzeća.

Provedeno istraživanje ima određena ograničenja koja se moraju istaknuti. Prvo ograničenje odnosi se na problem postavljanje kriterija za definiranje malih 
poduzeća zbog izostanka jedinstvenog pristupa definiranju malih poduzeća na državnoj razini u Bosni i Hercegovini. U ukupnom uzorku dominiraju mikro poduzeća sa udjelom od 52,83\% (prema kriteriju broja zaposlenih - $<10$ zaposlenih). S obzirom da se sustav nagrađivanja razvija paralelno s rastom broja zaposlenih u organizaciji, dominantan udio mikro poduzeća može prikazati krivu sliku o karakteristikama nagrađivanja u cijelom segmentu maloga gospodarstva. Anketni upitnik je strukturiran prema teorijskim konceptima kompenzacijskog menadžmenta koji uglavnom odražavaju sustave nagrađivanja velikih poduzeća. Nadalje, istraživanje je provedeno na prigodnom uzorku što onemogućuje primjenu zaključaka na sva mala poduzeća u BiH. Ograničenje je i izostanak kontrolnih varijabli u istraživanju.

\section{ZAKLJUČAK}

U teoriji menadžmenta ljudskih potencijala, i kompenzacijskog menadžmenta kao njegovog ključnog dijela, postoji nedovoljno istraženo područje vezano za primjenu suvremenih koncepata nagrađivanja u malim poduzećima. Menadžeri malih poduzeća uslijed organizacijskih i financijskih ograničenja nailaze na prepreke prilikom kreiranja i implementacije složenih sustava nagrađivanja. Privlačenje zaposlenika kroz kompenzacijske pakete u malim poduzećima često ne dolazi do izražaja jer osim što nema sustavnog pristupa nagrađivanju, poslodavci često nisu ni u mogućnosti osigurati atraktivne kompenzacijske pakete. Dodatno ograničenje predstavlja činjenica da su mala poduzeća manje poželjni poslodavci od velikih poduzeća.

Većina malih poduzeća nema odjel za ljudske potencijale, a politike, prakse i procedure upravljanja ljudskim potencijalima najčešće nisu formalizirane. Odlučivanje o plaćama i ostalim aspektima nagrađivanja je centralizirano i strogo kontrolirano od vrhovnih menadžera/vlasnika. U takvim je okolnostima izvršena analiza percepcija menadžera malih poduzeća o ulozi različitih aspekata materijalnog i nematerijalnog nagrađivanja. Analiza percepcija vlasnika ili menadžera malih poduzeća o različitim aspektima nagrađivanja je posljedično važna zbog utjecaja na stavove, aktivnosti i ponašanja menadžera, odnosno vlasnika malih i srednjih poduzeća u pogledu implementacije praksi nagrađivanja. Iako velika poduzeća uglavnom prepoznaju važnu ulogu kompenzacija za privlačenje, motiviranje i zadržavanje zaposlenika, istraživanje provedeno među menadžerima malih poduzeća pokazalo je da oni ne doživljavaju kompenzacije kao ključan faktor koji će pomoći u privlačenju i motiviranju zaposlenika. Pritom je važno istaknuti da menadžeri malih poduzeća koji nemaju većinski vlasnički udio u organizaciji pridaju veću važnost kompenzacijama u usporedbi s menadžerima koji su ujedno većinski vlasnici. 
Analiza pojedinačnih elemenata kompenzacijskog paketa pokazala je da menadžeri malih poduzeća uviđaju važnost analiziranih materijalnih i nematerijalnih nagrada. Visina osnovne plaće pritom se pokazala kao čimbenik koji prema mišljenju menadžera ima najveću ulogu u privlačenju i zadržavanju zaposlenika. U turbulentnom ekonomskom okruženju s ograničenim budžetom za ljudske potencijale nematerijalne strategije nagrađivanja mogu biti održiva alternativa materijalnim nagradama, što prepoznaju i menadžeri malih poduzeća. Pritom menadžeri malih poduzeća posebno prepoznaju ulogu kvalitete radnog života $i$ delegiranja odgovornosti.

S obzirom na sve dosadašnje teorijske spoznaje o važnosti i ulozi nagrađivanja, i menadžeri malih poduzeća trebali bi posvetiti odgovarajuću pažnju ovoj problematici. Nagrađivanje u malim poduzećima nije formalizirano, te stoga menadžeri imaju diskreciju definirati kompenzacije na način da se zadovolje individualne potrebe svakog zaposlenika. Krajnji učinak kompenzacija u malim poduzećima ovisiti će stoga o aktivnostima i postupcima menadžera. Istraživanje ukazuje da je među menadžerima malih poduzeća potrebno povećati svijest o važnosti kompenzacija i sustavnog pristupa kompenzacijama, posebno među vlasnicima poduzeća. Usprkos brojnim ograničenjima s kojima se susreću mala poduzeća, kompenzacije su još uvijek jedan od ključnih mehanizama kojima je moguće utjecati na ponašanje zaposlenika te je menadžerima malih poduzeća u interesu da iskoriste sav potencijal kompenzacija.

\section{LITERATURA}

1. Arbaugh, J. B., Cox, L. W., Camp, S. M. (2004) Employee Equity, Incentive Compensation, and Growth in Entrepreneurial Firms, New England Journal of Entrepreneurship, 7(1), str. 15-24.

2. Armstrong, M. (2005) A Handbook of Employee Rewards Management and Practice, 2. izd. London: Kogan Page.

3. Armstrong, M., Murlis, H. (2004) Reward Management. London: Kogan Page.

4. Bahtijarević-Šiber, F. (1999) Management ljudskih potencijala. Zagreb: Golden marketing.

5. Barrett, R., Mayson, S. (2007) Human resource management in growing small firms, Journal of Small Business and Enterprise Development, 14(2), str. 307-320.

6. Brand, M., Bax, H. (2002) Strategic HRM for SMEs: implications for firms and policy, Education + Training, 44(8/9), str. 451-463. 
7. Brewster, C., Wood, G., Brookes, M., van Ommeren, J. (2006) What determines the size of the HR function? A cross-national analysis, Human Resource Management, 45(1), str. 3-21.

8. Brush, C., Greene, P. G., Hart, M. M., Haller, H. S. (2001) From Initial Idea to Unique Advantage: The Entrepreneurial Challenge of Constructing a Resource Base [and Executive Commentary], The Academy of Management Executive (1993-2005), 15(1), str. 64-80.

9. Buble, M., Bakotić, D. (2013) Kompenzacijski menadžment. Split: Ekonomski fakultet u Splitu.

10. Buble, M., Klepić, Z. (2007) Menadžment malih poduzeća - osnove poduzetništva. Mostar: Ekonomski fakutet Sveučilišta u Mostaru.

11. Carlson, D.S., Upton, N., Seaman, S. (2006) The impact of human compensation design on performance: an analysis of family-owned SMEs, Journal of Small Business Management, 44(4), str. 531-543.

12. Carraher, S.M., Carraher, S.C. (2006) Human resource issues among SMEs in Eastern Europe: A 30 months study in Belarus, Poland and Ukraine, International Journal of Entrepreneurship, 10(1), str. 97-108.

13. Cegarra-Leiva, D., Sánchez-Vidal, M.E., Cegarra-Navarro, J.G. (2012) Understanding the link between work life balance practices and organisational outcomes in SMEs: The mediating effect of a supportive culture, Personnel Review, 41(3), str. 359-379.

14. Curran, J., Kitching, J., Abbott, B. and Mills, V. (1993), Employment and Employment Relations in the Small Service Sector Enterprise. London: Small Business Research Centre, Kingston Business School, Kingston University

15. De Kok, J. M. P., Uhlander, L. M., Thurik, A. R. (2002) Human Resource Management within small and medium-sized firms. Zoetermeer: EIM Business \& Policy Research.

16. Deshpande, S. P., Flanagan, D. J. (1995) Union Representation Elections in Large and Small Manufacturing Firms: a Comparative Study, Journal of Small Business Management, 33(1), str. 56-65.

17. Džafić, Z., Bejić, J. (2012) Poduzetništvo i tržište rada - Mala i srednja poduzeća u funkciji povećanja zaposlenosti. Zagreb - Sarajevo: Synopsis.

18. Europska komisija (2015). Vodič za korisnike o definiciji malih i srednjih poduzeća [online]. Luxembourg: Ured za publikacije Europske unije. Dostupno na: http://ec.europa.eu/DocsRoom/documents/15582/attachments/1/translations $/ \mathrm{hr} /$ renditions/native [05. kolovoza 2017.]

19. Eurostat (2017). Structural business statistics overview [online]. Luxembourg: Eurostat. Dostupno na: http://ec.europa.eu/eurostat/statistics-explained/ index.php/Structural_business_statistics_overview [05. kolovoza 2017.]

20. Galetić, L. (2015.) Kompenzacijski menadžment. Zagreb: Sinergija 
21. Gerhart, B., Milkovich, G. T. (1992) Employee Compensation: Research and Practice. U: Dunnette, M. D., Hough, L. M., ur., Handbook of Industrial \& Organizational Psychology, 2 izd. Palo Alto: Consulting Psychologists Press, Inc.

22. Gerhart, B., Milkovich, G. T., Murray, B. (1992) Pay, performance, and participation (CAHRS Working Paper \#92-28). Ithaca: Cornell University, School of Industrial and Labor Relations, Center for Advanced Human Resource Studies.

23. Gilman, M., Edwards, P., Ram, M., Arrowsmith, J. (2002) Pay determination in small firms in the UK: the case of the response to the National Minimum Wage, Industrial Relations Journal, 33(1), str. 52-67.

24. Heneman, H. G., Judge, T. A. (2000). Incentives and motivation. In: Rynes, S., Gerhart, B. (Eds.), Compensation in organizations: Progress and prospects. San Francisco: New Lexington Press, 61-103.

25. Hernaus, T., Aleksić, A. (2016) Unutarnji čimbenici organizacije, U: Galetić, L., ur., Organizacija, Zagreb: Sinergija-nakladništvo, str. 121-153.

26. Hope, K., ed. (2016). Annual Report on European SMEs 2015/2016: SME recovery continuous [online]. Bruxelles: European Commision. Dostupno na: https://ec.europa.eu/jrc/sites/jrcsh/files/annual_report_-_eu_smes_2015-16. pdf [05. kolovoza 2017.]

27. Huselid, M.A. (1995), The impact of human resource management practices on turnover, productivity, and corporate financial performance, Academy of Management Journal, 38, str. 635-72.

28. King-Kauanui, S., Ngoc, S. D., Ashley-Cotleur, C. (2006) Impact of Human Resource Management: SME performance in Vietnam, Journal of Developmental Entrepreneurship, 11(1), str. 79-95.

29. Martocchio, J. J. (2015) Strategic Compensation: A Human Resource Management Approach. 8. izd. Essex: Pearson Education Limited.

30. Mayson, S., Barret, R. (2006) The science and practice of HRM in small firms, Human Resource Management, 16(4), str. 447-455.

31. Memili, E., Misra, K., Chang, E. P. C., Chrisman, J.J. (2013) The propensity to use incentive compensation for non-family managers in SME family firms, Journal of Family Business Management, 3(1), str. 62-80.

32. Michiels, A. (2017) Formal compensation practices in family SMEs, Journal of Small Business and Enterprise Development, 24(1), str. 88-104.

33. Milkovich, G. T., Newman, J. M. (2005) Plaće i modeli nagrađivanja, Zagreb: Masmedia.

34. Ministarstvo privrede Kantona Sarajevo (2016). Program razvoja male privrede za period 2016-2019 godine [online]. Sarajevo: Ministarstvo privrede Kantona Sarajevo. Dostupno na: http://mp.ks.gov.ba/preuzimanja/ 
publikacije/program-razvoja-male-privrede-za-period-2016-2019-godina [22. kolovoza 2016.]

35. Ministry of Economy, Trade and Industry (1999). Small and Medium-sized Enterprise Basic Act [online]. Small and Medium Enterpise Agency. Dostupno na : http://www.chusho.meti.go.jp/sme_english/outline/08/01_01.html [05. kolovoza 2017.]

36. Mukhopadhyay, A. K., Pendse, S. (1983) Profit Sharing in Small Business: An Analysis of Risk and Incentive Effects, American Journal of Small Business, 7(4), str. 31-37.

37. Newman, A., N., Sheikh, A. Z. (2014) Determinants of best HR practices in Chinese SMEs, Journal of Small Business and Enterprise Development, 21(3), str. 414-430.

38. OECD (2016). Entrepereneurship at a Glance 2016 [online]. Paris: OECD Publishing. Dostupno na: http://dx.doi.org/10.1778/enterpreneur_aag-2016en [06. kolovoza 2017.]

39. Officional Journal of European Union (2003) Commission Recommendation of 6 May 2003 concerning the definition of micro, small and medium-sized enterprises. Bruxelles: European Commision, 2003 (361), str. 35-41.

40. Prouska, R., Psychogios, A. G., Rexhepi, Y. (2016) Rewarding employees in turbulent economies for improved organisational performance: Exploring SMEs in the South-Eastern European region, Personnel Review, 45(6), str. 1259-1280.

41. Psychogios, A.,Szamosi, L. T., Prouska, R., Brewster, C. (2016) A three-fold framework for understanding HRM practices in South-Eastern European SMEs, Employee Relations, 38(3), str. 310-331.

42. Richbell, S., Laszlo, S., Vitai, Z. (2010) HRM in the hungarian SME sector, Employee Relations, 32(3), str. 262-280.

43. Robu, M. (2013) The Dynamic and Importance of SMEs in Economy, The USV Annals of Economics and Public Administration, 13(1), str. 84-89.

44. Singer, S., ur. (2016). Izvješće o malim i srednjim poduzećima u Hrvatskoj2016. [online]. Zagreb: CEPOR. Dostupno na : http://www.cepor.hr/wp-content/uploads/2015/04/Cepor-izvjesce-2016-HR-web.pdf [05. kolovoza 2017.]

45. Singh, M., Vohra, N. (2009) Level of formalisation of human resource management in small and medium enterprises in India, Journal of Entrepreneurship, 18(1), str. 95-116.

46. Stines, S. R., Kleiner, B. H. (2003) Keys to hiring employees effectively in a small business, Management Research News, 26(2/3/4), str. 170-180.

47. Škrtić, M., Mikić, M. (2011) Poduzetništvo. Zagreb: Sinergija.

48. Tansky, J., Heneman, R. (2003) Guest editor's note: introduction to the special issue in human resource management in SMEs: a call for more research, Human Resource Management, 42(4), str. 299-302. 
49. Thorpe R. i Homan, G. (2000)., Strategic Reward Systems. Harlow: Prentice Hall

50. Varum, C.A., Rocha, V.C. (2013) Employment and SMEs during crises, Small Business Economics, 40(1), str. 9-25.

51. Wilkinson, A. (1999) Employment relations in SMEs, Employee Relations, 21(3), str. 206-217.

52. World Trade Organization (2016). World Trade Report 2016: Levelling the trading field for SMEs. [online]. Geneva: World Trade Organization. Dostupno na: https://www.wto.org/english/res_e/booksp_e/world_trade_report16_e.pdf [07. kolovoza 2017.]

53. Zhend, C., O’Neil, G., Morrison, M. (2007) Ownership and strategic choice of HRM methods by Chinese SMEs, Asia Pacific Journal of Economics and Business, 11(1), str. 25-39. 
Ivana Načinović Braje, Ph.D.

Faculty of Economics \& Business, University of Zagreb, Zagreb, Croatia Ivana.nacinovic@efzg.hr

Luka Bosnić, mag. oec.

Corrado d.o.o. Mostar

info@corrado.ba

\title{
EMPLOYEE COMPENSATION IN SMALL ENTERPRISES: CURRENT STATUS AND ROLE FROM MANAGERIAL PERSPECTIVE
}

Review

\begin{abstract}
Compensation management is an essential part of the human resource management. In order to increase market competitiveness and to attract and retain key employees, small enterprises must also pay attention to employee reward. Due to the fact that human resource management, as well as compensation management, is less formalized within small enterprises when compared to large ones, the existing knowledge on compensation management within large enterprises cannot be transferred to small enterprises. In small enterprises owners/managers themselves design compensation packages that should attract, motivate and retain employees.

In order to understand current status and the role of compensation management within small enterprises a research was conducted among managers of small enterprises in Bosnia and Herzegovina. In general, respondents do not find compensation to be the key element in attracting and retaining employees in small enterprises. Still, there are some differences among respondents based on their position within the company. Managers that do not have a majority ownership stake in the company give more importance to employee compensation. Additional analysis of selected transactional and intrinsic rewards and their role in improving motivation has shown that highest rated factor was base pay. Besides base pay, respondents emphasized the quality of work life and sharing responsibility. Although small enterprises managers'do not find compensation as the key for improving motivation, they are aware of the importance of selected compensation elements, both transactional and intrinsic ones.
\end{abstract}

Keywords: employee compensation, material compensation, nonmaterial compensation, small enterprises

JEL: M52 